\title{
Reducing Food Waste During COVID-19: Testing Role Model Stories as a Strategy for Promoting Conservation Behaviors
}

\author{
Nicole Hummel O’Donnell ${ }^{1 *}$, Ismail Karabas ${ }^{2}$ and Aloni Hill ${ }^{1}$ \\ ${ }^{1}$ Virginia Commonwealth University, Richmond, VA, United States, ${ }^{2}$ Murray State University, Murray, KY, United States
}

This study investigates how role model stories may inspire food waste reduction during times of perceived food scarcity. We conducted a $2 \times 2$ between-subjects experiment $(N=$ 358 , U.S. adults) to test the effectiveness of messages that emphasized role model success (reduced waste/zero-waste) and achievement difficulty (easy/difficult) on intentions to set a personal food waste goal. Exposure to role models who lived a zero-waste lifestyle had a self-deflating effect, as this behavior was viewed as less attainable by participants. Regardless of difficulty framing, exposure to role models

OPEN ACCESS

Edited by:

Anna Maria Jönsson, Södertörn University, Huddinge,

Sweden

Reviewed by:

FatimaViteri,

Aix-Marseille Université, France

Hang Lu,

University of Michigan, United States

*Correspondence: Nicole Hummel O'Donnell naodonnell@vcu.edu

Specialty section: This article was submitted to

Science and Environmental Communication, a section of the journal Frontiers in Communication

Received: 10 September 2021 Accepted: 10 January 2022 Published: 23 February 2022

Citation:

O'Donnell NH, Karabas I and Hill A (2022) Reducing Food Waste During COVID-19: Testing Role Model Stories as a Strategy for Promoting

Conservation Behaviors.

Front. Commun. 7:774009.

doi: $10.3389 /$ fcomm.2022.774009 who reduced their waste enhanced participants' perceptions of goal attainability, motivation, and intentions. No interaction effects were found between levels of success and achievement difficulty. Considering covariates, individuals who reported enhanced food waste awareness due to COVID-19 reported higher goal setting intentions. Hence, times of perceived food scarcity may provide an ideal opportunity for promoting food waste reduction and conservation strategies. Results from this study provide guidance for how role model stories can best inspire waste reduction without hindering attainability and motivation. We discuss implications for applying the motivational theory of role modeling in conservation and communication contexts.

Keywords: COVID-19, expectancy motivation, food waste reduction, goal setting, role model behavior

\section{INTRODUCTION}

An estimated one fourth of all food produced for human consumption is lost or wasted (Kummu et al., 2012). In the United States, rates are higher than the international average with $30-40 \%$ of food lost or wasted annually (United States Food and Drug Administration, 2021). Chen et al. (2020) found that food waste in high income countries is four to six times higher than food waste in lower income countries. There are several negative outcomes associated with food waste. Food waste contributes to the depletion of freshwater resources, land, and fossil fuels (Munesue et al., 2015). In addition, the decomposition of food waste releases excessive $\mathrm{CO}_{2}$ and methane emissions, which negatively affects global climate change (Chen et al., 2020). According to Project Drawdown, reducing food waste and loss are key climate solutions that need public attention (Hawken, 2017). Food waste reduction does not receive as much public attention as other conservation behaviors such as recycling or reducing single-use plastics (Thyberg and Tonjes, 2016). However, there has been a renewed interest in this topic in recent years and the United Nations included aims to halve food waste by 2030 as part of their official Sustainable Development Goals (Heller, 2019). 
Food waste occurs across the food chain, yet approximately half of all food waste happens at the household level in industrialized countries (Parfitt et al., 2010; Stancu et al., 2016). Several studies infer that the public lacks awareness and knowledge of food waste problems, as well as subsequent motivations to reduce waste (Doron, 2013; Quested et al., 2013). A family of four wastes an estimated $\$ 1,500$ worth of food every year (Buzby et al., 2014). Households most frequently waste food that spoils or is ruined during cooking, or food that there is an unwanted abundance of, such as leftovers or disliked foods (Parfitt et al., 2010). Some individuals report that overpurchasing and having an abundance of food are signs of being a good provider for one's family (Graham-Rowe et al., 2014). Other reasons for an excess of food waste include poor shopping preplanning, impulse buying, a misunderstanding of food labels, poor food storage, inadequate portion control, and aversion to leftovers (Parfitt et al., 2010). Research from the United States and Italy suggests that times of perceived food uncertainty, such as the COVID-19 pandemic, can make people more aware of their food waste (Rodgers, et al., 2021). There is an urgent need for food waste reduction, and COVID-19 has created a timely opportunity to raise awareness to this issue.

In the current study, we are interested in understanding how individuals process media messages aimed at reducing food waste. Food waste is a habitual behavior and social influence of others may especially be important in changing food waste behaviors (Comber and Thieme, 2013). A common way that mass media promote food waste reduction is through the use of role model stories. In these stories, successful role models share the steps that they took to go zero-waste or reduce their personal waste and describe resulting positive outcomes (Ramos and Cownie, 2020). Role models are frequently featured in news (e.g., "Composting Has Been Scrapped. These New Yorkers Picked Up the Slack", New York Times, 2020), magazines (e.g., "How Zero-Waste People Make Only a Jar of Trash a Year", National Geographic, 2018), and social networking sites (e.g., @zerowastechef on Instagram, Twitter, and Facebook). Role model stories are also utilized in behavior change campaigns, such as featured chefs in the Waste Not Want Not social marketing program (Kim et al., 2020). There is a lack of research on the characteristics that role models need to possess for role aspirants to view them as inspirational. In the current study, we analyze two role model characteristics that may be important in promoting food waste goal setting: a role model's level of success at reducing waste, and how easy or difficult it is to achieve this success. A useful framework for analyzing these characteristics is the motivational theory of role modeling (Morgenroth et al., 2015). Drawing on social cognitive theory (Bandura, 1986) and expectancy literature (Vroom, 1994), this theory suggests that role models inspire role aspirants through promoting goal attainability, and enhancing outcome expectancies, motivation, and goal adoption.

Taken together, the overall inquiry for this research is to understand how a role model's level of success and achievement difficulty affect a role aspirant's process of forming, and intending to achieve, a personal food waste reduction goal during the COVID-19 pandemic. This is the first study to our knowledge that tests a core proposition of the motivational theory of role modeling in an environmental behavioral context. Findings will give researchers key insights into the variables that affect perceptions of food waste reduction. Furthermore, our investigation will offer a deeper understanding of the factors that broadly facilitate or hinder the effectiveness of role model stories for mass media promotion of conservation behaviors. The following literature review includes an overview of role model stories, how these stories may affect food waste reduction attainability, expectancies, and motivation, and why it is salient to analyze this topic during the COVID-19 pandemic.

\section{ROLE MODEL STORIES}

Role models often inspire individuals to set goals and practice behaviors needed to achieve desired outcomes. In the motivational theory of role modeling, Morgenroth et al. (2015) refer to individuals who are actively inspired by role models as role aspirants. Through the role modeling process, role aspirants create and benefit from role models both consciously and subconsciously. This theory proposes that role models function in three distinct ways: they represent the possible, they are inspirational, and they act as behavioral models (Morgenroth et al., 2015).

Environmental beliefs and attitudes are established at a young age with research emphasizing the importance of parents and educators as role models (Stevenson et al., 2014; Öztürk, 2016). When conducting in-depth interviews to explore barriers that individuals face when trying to minimize food waste, GrahamRowe et al. (2014) found that food management skills are directly taught or implicitly acquired through modeling parents and important others. Most role model literature is grounded in social cognitive theory (Bandura, 1986). According to this theory, exposure to the steps that an individual takes to reduce or eliminate food waste and the subsequent rewards of this behavior may give an individual a model for how to implement similar standards in their own life.

Research on environmental role models is scarce, with some studies addressing the importance of educators in engaging young individuals in promoting science, technology, engineering and mathematics (STEM) academic and career interest and success (Sivek and Hungerford, 1990; Quimby et al., 2007; Luong et al., 2020). However, implications can be gleaned from these studies, specifically detailing how levels of success and achievement difficulty affect attainability perceptions, outcome expectancies, motivation, and in turn, goal setting intentions.

\section{Attainability}

An important antecedent to goal setting is perceived attainability, which refers to an individual's perceptions that favorable conditions exist in one's life to achieve a desired goal (Stefanic et al., 2017). The pursuit of attainable personal goals can have a positive effect on an individual's psychological well-being (MacLeod et al., 2008). Based on the motivational theory of role modeling (Morgenroth et al., 2015), we propose that 
perceived attainability of food waste reduction or elimination is an essential first step for promoting goal setting. Locke and Latham, (1990) goal setting theory posits that setting difficult, but attainable goals, leads to higher achievement than setting easier goals. However, several studies have been unable to support this position. For example, Plys and Desrichard (2020) found that perceiving a health goal as difficult was negatively correlated with attainability. Similarly, Tenenbaum et al. (1999) were unable to support this position within a sports performance context. If individuals believe conservation behaviors are easy, they may be more likely to take part in these behaviors out of convenience (Oskamp, 1995). However, if conservation behaviors are seen as difficult, but worthwhile, individuals may feel that the outcomes or rewards are greater, and in turn have higher self-determination or motivation to take part in the behavior (Green-Demers et al., 1997). These potential effects need further investigation. In addition to viewing a behavior as attainable, individuals must also associate positive outcome expectancies with the behavior (Morgenroth et al., 2015).

\section{Expectancy}

Throughout the years, several theorists have operationalized and evaluated the importance of perceived outcome expectancies. Rotter (1954, p. 112) defined expectancy as "the subjective probability held by the individual that a particular reinforcement will occur as a function of, or in relation to, a specific behavior in a given situation or situations." To be effective, role model stories must focus on the many positive outcomes of reducing personal food waste, which include frugality, saving money, living sustainably, and eating healthier (Raghunathan and Chandrasekaran, 2021; Thyberg and Tonjes, 2016). The greater an individual views the outcomes associated with food waste reduction, the more they will be motivated to change their behavior (Morgenroth et al., 2015).

\section{Motivation}

It is well-established that role models can inspire role aspirants. Conceptually, inspiration is a motivational state in which influences move an individual toward something better (Thrash and Elliot, 2004). Beyond known behavior models such as parents and educators, vicarious learning can happen through viewing mass media depictions of behavior change (Bandura and Walters, 1977). Greta Thunberg is an example of an inspirational environmental role model who recently motivated an estimated 7.6 million $^{1}$ individuals worldwide to take part in School Strike for Climate protests. Mass media use the phrase the "Greta Effect" to reference Thunberg's influence on inspiring youth climate activists across the globe (Jung et al., 2020). Similarly, researchers have analyzed how famous scientists and public figures such as Jane Goodall, Leonardo DiCaprio, and Arnold Schwarzenegger have inspired public engagement with environmental issues (Hultman, 2013; Leas et al., 2016; Cavallaro et al., 2017). These inspirational environmental role models have

${ }^{1}$ Attendance estimate from the organizer 350.org. Retrieved from https://350.org/ 10-years/ undoubtedly helped to inform public opinion; however, an issue with eco-celebrities acting as role models is that their level of success, while inspirational, may not be viewed as attainable.

Celebrity or "superstar" role models can have a self-deflating effect on a role aspirant's motivation if a desired behavior is not viewed as attainable (Lockwood and Kunda, 1997). For this reason, Birmingham and LeQuire (2010) suggest that besides ecocelebrities, mass media and individuals in positions of influence should elevate the voices of citizen environmentalists. Citizen role models may be better at modeling attainable and relatable behavior than celebrity role models (Martensen et al., 2018). There is a lack of research on how individuals perceive citizen role models in news and popular media who are not famous. Newspapers, magazines, television programs and social networking sites frequently feature role model stories that describe how an individual works to better their environment. Considering the importance of attainability, outcome expectancies, and motivation in the role model process, it is of interest to see how individuals respond to citizen environmentalist role models, and what other contextual factors may affect this process.

\section{Contextual Factors}

Perceptions of food scarcity are especially salient for promoting food waste reduction. For example, an emerging body of research suggests that perceived food scarcity related to the COVID-19 pandemic has increased food waste awareness (Ben Hassen et al., 2020; Jribi et al., 2020; Kumar and Dwivedi, 2020; Laato et al., 2020; Richards and Rickard, 2020; Roe et al., 2020; Principato et al., 2020). A study from Italy showed that the onset of COVID-19 led citizens to care more about reducing their household food waste (Principato et al., 2020). Similarly, survey data from Qatar showed that individuals in the country did not partake in panic buying, and respondents reported an overall decrease in household food waste (Ben Hassen et al., 2020). Better waste reduction behaviors were also reported in Tunisia, with researchers suggesting that perceptions of food scarcity, lockdown measures, and loss of income motivated these behaviors (Jribi et al., 2020). Individuals in India reported cooking more, spending more time in the kitchen, and repurposing food for leftovers as a means to decrease waste during the pandemic (Kumar and Dwivedi, 2020). In contrast to the positive effects of COVID-19 on household food waste, Richards and Rickard (2020) suggested that an impact on the Canadian food market included more produce purchases and a subsequent increase in perishable waste. Furthermore, panic buying and food hoarding, which increased worldwide due to COVID-19 (Laato et al., 2020), led to more waste. Roe et al. (2020) suggested that individuals may have over-bought food or brands that they dislike in a panic. Taken together, these studies suggest that COVID-19 has led the way for potential breakthroughs in raising awareness to a need for food waste reduction. However, to our knowledge, message strategies for promoting food waste reduction during COVID-19 have yet to be analyzed. To test how effective role model message strategies may affect food waste reduction goal setting outcomes (e.g., attainability, expectancy, motivation, and intentions), we propose the following two research questions: 
RQ1: How does exposure to role model messages, that vary based on level of success and behavioral difficulty, affect goal setting outcomes?

RQ2: To what extent do COVID-19 contextual factors, including increased food waste awareness and reported food hoarding affect goal setting outcomes?

\section{METHODS}

\section{Protocol and Sample Characteristics}

We conducted an online between-subjects experiment with a total of 358 U.S. adults. Participants came from a Qualtrics panel. Qualtrics aims to recruit samples that mirror U.S. census data (Qualtrics, 2021). Comparative research shows that Qualtrics panels provide a better representation of U.S. adults than other similar options, such as Facebook or Mechanical Turk (Boas et al., 2020). We chose to include quotas for sex and race during data collection to ensure these categories did not have an over-representation of female or white respondents, as shown in former research (Heen et al., 2014; Boas et al., 2020). Respondents reported their sex as male (50.6\%) or female (49.4\%). Participants ranged from ages $18-80(M=39.07, S D=16.81)$. Race/ethnicity categories were not mutually exclusive. Respondents identified their race/ethnicity as white $(n=240)$; Hispanic or Latinx $(n=$ 57); Black or African American $(n=43)$; Asian $(n=25)$; American Indian or Alaska Native $(n=4)$; Native Hawaiian or Pacific Islander $(n=2)$; and other $(n=6)$.

Data collection took place over a three-day period in March 2020, following the declaration of COVID-19 as a pandemic. Individuals consented to take part in this survey and verified that they were over the age of 18 and a U.S. resident. They answered demographic questions and then they viewed one of four message exposure conditions: 1) reducing waste is easy, 2) reducing waste is difficult-but worth it, 3) going zero-waste is easy, or 4) going zero-waste is difficult-but worth it. After message exposure, all participants answered questions pertaining to the study outcomes and mediators. The survey took participants an average of 10.5 min. Qualtrics compensated individuals with a monetary payment, gift card, or consumer reward equal to $\$ 5.00$ in value. A university Institutional Review Board declared this study as exempt from review.

\section{Measures}

Attainability. One question adapted from Kim et al. (2013) measured attainability: "Setting a goal related to food waste seems attainable to me." Responses were measured from "strongly disagree" = 1 to "strongly agree" = $7(M=5.50$, $S D=1.29$ ).

Expectancy. Participants stated how much they believed that setting a food waste goal would help them "save money," "be more environmentally friendly," and "be healthier." Responses were measured from "strongly disagree" = 1 to "strongly agree" = 7 and the three items were averaged to create an expectancy scale $(M=5.75, S D=1.02, \alpha=0.76)$. Expectancy questions were adapted from research by Kim et al. (2013) and Quested et al. (2013).
Motivation. One question adapted from Abeliotis et al. (2014) was used to measure motivation: "How motivated are you to set a goal related to food waste for your household?" Responses were measured from "not at all" $=1$ to "a great deal" $=5(M=3.60$, $S D=1.09)$.

Goal intentions. One question adapted from Kim et al. (2013) measured goal intentions: "I plan to set a goal related to food waste in my household this week." Responses were measured from "strongly disagree" $=1$ to "strongly agree" $=7(M=4.93, S D$ $=1.50$ ). We chose not to use the terms "reduce waste" or "zerowaste" in this measure to ensure that all participants answered questions with the same outcome anchor.

COVID-19 food waste awareness. We asked participants one question to address COVID-19 food waste awareness: "To what extent do you think the recent coronavirus outbreak (COVID-19) has made you more aware of your food waste than normal?" Response options were measured on a five-point Likert-type scale from "not at all" $=1$ to "a great deal" $=5(M=2.92, S D=1.41)$.

COVID-19 food hoarding. We asked participants, "To what extent do you feel like you have over-bought food or supplies due to the recent coronavirus outbreak (COVID-19)?" Response options were measured on a five-point Likert-type scale from "not at all" $=1$ to "a great deal" $=5(\mathrm{M}=2.01, \mathrm{SD}=1.18)$.

\section{Stimuli Design}

Experimental stimuli were created using a news template in Photoshop. The messages contained a role model story written in a question-and-answer format with a hypothetical role model named Taylor. All of the stories began with a definition of food waste and common examples of preventable food waste adapted from Parfitt et al. (2010). Then, the stimuli included food waste strategies with wording varying based on the condition individuals were assigned to. We discussed strategies for reducing waste or going zero-waste, and then described these strategies as either easy or difficult-but worth it. The strategies in the stimuli were based on the U.S. Environmental Protection Agency (2021). They included, making a shopping list, storing food properly, prepping perishables, setting food waste goals, purchasing products to store leftovers, composting, and eating food before buying more. The stimuli were vetted by a team of three researchers and tested in a pilot study. Furthermore, a roundtable of local environmental stakeholders, including individuals from academia, local conservation districts, and non-profit organizations reviewed the study protocol before data collection. All study stimuli are available for replication purposes (Figure 1).

\section{Stimuli Pilot Study}

We used a pilot study to test our stimuli manipulations. Hauser et al. (2018) state that manipulation checks conducted in an experiment can "amplify, undo, or interact with the effects of a manipulation" (p. 1). One way to reduce confounding effects is to analyze message effectiveness in a pilot study (Hauser et al., 2018). Our goal for this research was to understand how individuals perceive role models that frame achieving zerowaste or reducing waste as easy or difficult. The stimuli reference reducing waste or going zero-waste 12 times and the 


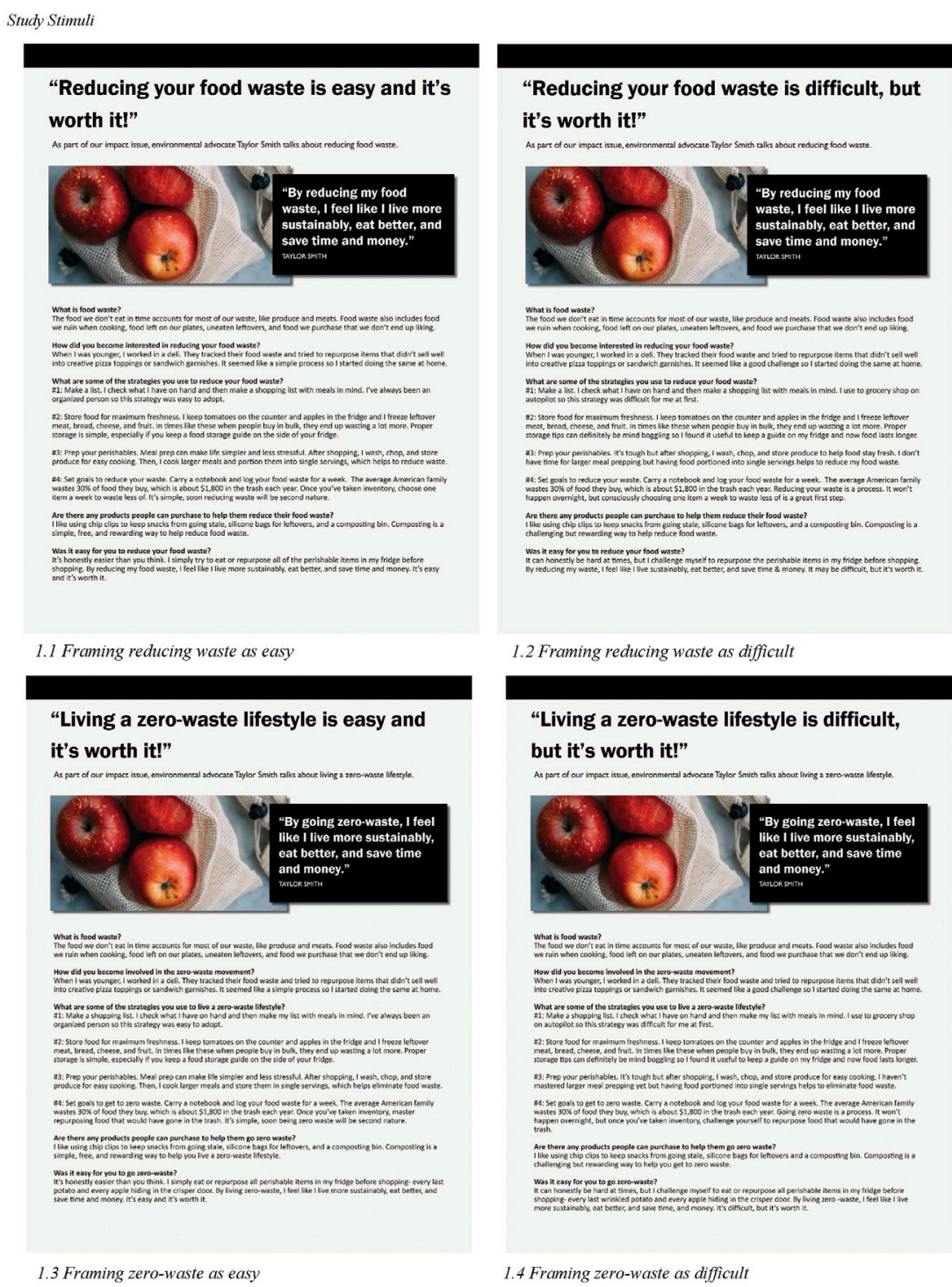

FIGURE 1 | Experimental Stimuli Manipulations.

level of difficulty 8 times. We used a pilot study to see how likely individuals were to recognize these manipulations.

We conducted the pilot-study with 65 survey participants from Amazon's Mechanical Turk online survey platform. Individuals were randomly assigned to read one of the four stimuli iterations. First, we analyzed if individuals noticed the references to "reduce waste" or "zero-waste." Results from a chi-square test showed that most individuals identified the condition that they were assigned to (reduce waste: 33 correct, 1 incorrect) (zero-waste: 30 correct, 1 incorrect) $\left[x^{2}(3,1)=58.45, p=0.000\right]$. Next, we asked individuals to identify how the article that they read described food waste reduction or elimination on a seven-point Likert type scale from 1 = "extremely difficult" to 7 = "extremely easy." Results from a Welch's t-test showed that individuals in the easy conditions rated the articles as stating that goal setting was easier $(M=3.94, \mathrm{SD}=$
$0.18)$ than individuals in the difficult conditions $(M=1.90, \mathrm{SD}=$ 1.37) $[t(56.88)=-6.63, p<0.001]$. We also asked a question about perceptions of Taylor's sex, with individuals stating they could not discern Taylor's sex (50\%), or that they thought Taylor was female (34.8\%), or male (15.2\%). Then, we asked individuals how much they agreed that Taylor was a role model on a scale of from $1=$ "strongly disagree" to 7 = "strongly agree." Results from a one-way ANOVA with a post-hoc Tukey test showed that individuals' perceptions of Taylor as a role model did not vary based on whether they perceived Taylor to be male $(M=5.80)$, female $(M=5.70)$, or of unknown $\operatorname{sex}(M=5.58)[F(2,63)=0.23, p=0.79]$.

\section{Analytical Strategy}

For our main experiment, we used a series of two-way analysis of variance (ANOVA) models to test the effects of message exposure 


\section{Serial mediation model for message exposure on goal intention}

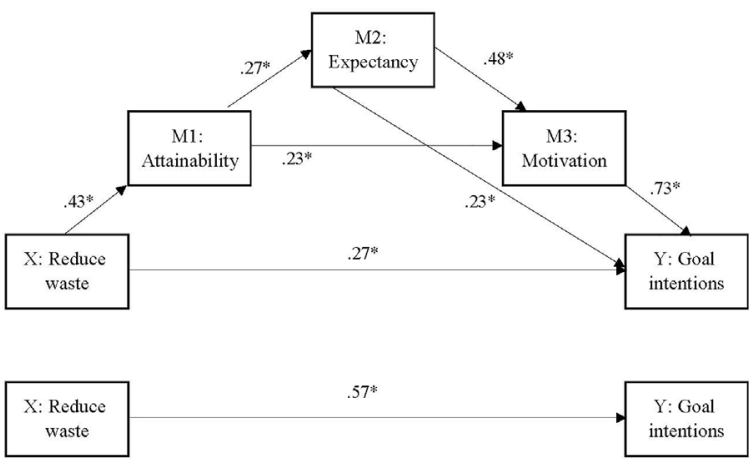

Indirect effect of $X$ on $Y$ throurgh $M 1$ and $M 2$ in serial: $0.02,95 \% \mathrm{CI}: 0.00,0.06$ Indirect effect of $\mathrm{X}$ on $\mathrm{Y}$ throurgh $\mathrm{M} 1$ and $\mathrm{M} 3$ in serial: $0.07,95 \% \mathrm{CI}: 0.02,0.14$ Indirect effect of $\mathrm{X}$ on $\mathrm{Y}$ through M1, M2, and M3 in serial: $0.04,95 \% \mathrm{CI}: 0.01,0.08$

${ }^{*} \mathrm{p}<05$

FIGURE 2 | Serial Mediation Model for Message Exposure on Goal Intentions.

on attainability, expectancies, motivation, and intentions. Then, we used a serial mediation model to analyze the effects of message exposure on intentions through attainability, expectancy, and motivation, as serial mediators (PROCESS Model 6; Hayes, 2019). Covariates in the mediation model included a reported increase in food waste awareness and food hoarding due to COVID-19.

There were several steps that we took to consider data assumptions. We used a Qualtrics randomizer with a count feature to ensure random assignment and equal distribution between conditions. We inspected box plots to ensure the assumption of normality was upheld across conditions and outcomes. Additionally, Levine's tests for homogeneity of variance found equal variance between groups for our outcome measures of attainability $[F(3,354)=2.54, p=0.06]$, expectancies $[F(3,354)=1.49, p=0.21]$, motivation $[F(3,354)=2.19$, $p=0.09]$, intentions $[F(3,354)=2.39, p=0.07]$.

We also checked to make sure that the COVID-19 variables were not affected by the study manipulations. Results from a two-way ANOVA showed that message exposure did not affect reporting an increase in food waste awareness due to COVID-19 $[F(1,354)=$ $0.18, p=0.90$ ] or reporting an increase in food hoarding due to COVID-19 $[F(1,354)=0.15, p=0.95]$.

\section{RESULTS}

The first research question asked about how message exposure affects perceived attainability, motivation, expectancy, and goal setting intentions. Results from a series of two-way ANOVAs showed significant main effects of the level of success on perceived attainability $[F(1,354)=10.88, p=0.001, \eta 2=$ $0.030]$, motivations $[F(1,354)=2.85, p<0.05, \eta 2=0.024]$, and goal setting intentions $[F(1,354)=13.29, p=0.000 \eta 2=$ 0.036]. Pairwise comparisons showed that viewing a waste reduction role model led to higher perceived attainability $(M=$ $5.72, S D=1.10)$ than a zero-waste role model $(M=5.28, S D=$
1.43). Exposure to the waste reduction role model also led to higher goal setting motivation $(M=3.72, S D=1.02)$ compared to the zero-waste role model $(M=3.39, S D=1.14)$. Additionally, exposure to the waste reduction role model led to higher goal setting intentions $(M=5.22, S D=1.37)$ than exposure to a zerowaste role model $(M=4.65, S D=1.56)$. There was a nonsignificant main effect of level of success on outcome expectancies. Rather, there was a significant main effect for level of difficulty on outcome expectancies $[F(1,354)=6.02$, $p=0.01, \eta 2=0.017]$. Viewing messages that discussed setting a food waste goal as difficult-but worth it led to higher outcome expectancies $(M=5.88, S D=0.95)$ than viewing messages that discussed setting a food waste goal as easy $(M=5.61, S D=1.08)$. No interaction effects between conditions were observed.

Considering the finding that the level of difficulty manipulation did not affect intentions, we simulated a mediation model to analyze the crossover effects of level of success on goal setting intentions ${ }^{2}$. Results from the serial mediation model showed an indirect path from viewing role model messages that promoted reducing waste (compared to zero-waste) to goal setting intentions through increased attainability, expectancy, and motivation, in serial (point estimate $=0.04, S E=0.01,95 \% C I: 0.01,0.08$ ) (Figure 2). Indirect paths were also observed for waste reduction messages to goal intentions through perceived attainability and outcome expectancies in serial (point estimate $=0.02, S E=$ $0.01,95 \% C I: 0.00,0.06)$, and for perceived attainability and motivation in serial (point estimate $=0.07, S E=0.03,95 \% C I$ : $0.02,0.14)$.

The second research question asked how COVID-19 food waste awareness and food hoarding affect food waste outcomes. Individuals who reported an increase in food waste awareness due to COVID-19 reported perceptions of food waste reduction attainability, expectancies, and motivation (Table 1). Furthermore, in the total effects model, heightened food waste awareness due to COVID-19 led to higher intentions to set a food waste goal. Whereas, reporting food hoarding due to COVID-19 did not affect personal food waste outcomes. Overall, COVID-19 factors accounted for $9.51 \%$ of the variance in predicting food waste intentions $[F(3,354)=12.39, p=0.000]$. When including message exposure, attainability, expectancies, and motivation, the model accounted for $48.58 \%$ of the variance in predicting intentions $[F(6,351)=55.26, p=0.000]$.

\section{DISCUSSION}

The findings from this research present possible ways that role model stories can promote conservation behaviors. These

${ }^{2} \mathrm{We}$ also simulated a more complex moderated mediation model (PROCESS Model 85, Hayes, 2019) with level of difficulty added as a moderator. Consistent with results from the two-way ANOVA, the two conditions did not interact to affect attainability, expectancies, motivation, or intentions, and there was no evidence of moderated mediation. Based on the principle of parsimony, a simplified mediation model that analyzed the crossover effects of level of success on intentions regardless of level of difficulty is presented here. 
TABLE 1 | Path Coefficients for Predicting Goal Setting Intentions.

\begin{tabular}{|c|c|c|c|c|c|}
\hline & To attainability & To expectancies & To motivation & $\begin{array}{l}\text { To Intentions } \\
\text { (direct effects) }\end{array}$ & $\begin{array}{l}\text { To Intentions } \\
\text { (total effects) }\end{array}$ \\
\hline COVID-19 food waste awareness & $0.16(0.05)^{\star \star}$ & $0.18(0.03)^{\star \star \star}$ & $0.07(0.03)^{\star}$ & $0.02(0.04)$ & $0.25(0.05)^{\star \star \star}$ \\
\hline COVID-19 food hoarding & $-0.08(0.06)$ & $-0.06(0.04)$ & $0.00(0.04)$ & $0.06(0.05)$ & $0.00(0.06)$ \\
\hline X: Reduce waste $=2$ (zero waste $=1)$ & $0.43(0.13)^{\star \star}$ & $0.04(0.09)$ & $0.15(0.09)$ & $0.27(0.11)^{\star}$ & $0.57(0.15)^{\star \star \star}$ \\
\hline Ml: Attainability & - & $0.27(0.03)^{\star \star \star}$ & $0.23(0.03)^{\star \star \star}$ & $0.03(0.05)$ & - \\
\hline M2: Expectancies & - & - & $0.48(0.04)^{\star \star \star}$ & $0.23(0.07)^{\star \star \star}$ & - \\
\hline M3: Motivation & - & - & - & $0.73(0.06)^{\star \star \star}$ & - \\
\hline
\end{tabular}

${ }^{*} p<0.05,{ }^{* *} p<0.01,{ }^{* * *} p<0.001$

findings also provide unique insight for how to communicate food waste reduction during COVID-19 or other times of perceived food scarcity. This study takes a small step forward in testing theoretical positions from the motivational theory of role modeling in an environmental communication context.

Results from the mediation model reveal the critical importance of attainability as an antecedent to the goal setting process. The motivational theory of role modeling (Morgenroth et al., 2015) proposes a theoretical path from attainability to goal setting through both expectancies and motivation in serial. The current study showed that the level of a role model's success can affect these antecedents. Specifically, a role model's level of success must be viewed as attainable to affect goal intentions through enhancing positive expectancies and motivation. Importantly, the results also showed two indirect paths from attainability to intentions. The first was solely through enhancing positive expectancies, and the second was solely through enhancing motivation. Paths that did not include perceived attainability were not significant. Thus, these results suggest that waste reduction messages should include actionable steps for waste reduction that are possible for everyday consumers.

Regarding outcome expectancies, these results support that emphasizing the challenges individuals face when setting a goal can potentially increase perceptions of positive outcomes. These findings align with research that states individuals may have a greater sense of self-determination if they perceive a behavior as difficult to carry out (Green-Demers et al., 1997). However, without also seeing the behavior as attainable, this increase in positive expectancies does not translate to an increase in goal setting intentions. Our findings provide some nuance for how these role model characteristics affect the process of goal setting, with greater investigation into the null effects needed. One reason for these effects may be that all of the messages that individuals read promoted the same positive outcome expectancies as those listed in the survey questions (e.g., saving money, being more environmentally friendly, and being healthier). Future research may consider manipulating outcome expectancies to see how behavior goal setting varies based on personal and societal outcomes.

Next, we analyzed the impact of these messages on perceived motivation. Environmental role models that promote a zerowaste lifestyle are frequently featured in mass media as exemplars of conservation (Murphy, 2019; Ramos and Cownie, 2020). While inspirational, these role models may be making waste reduction appear less attainable. Findings from the current study support research from the field of education (Lockwood and Kunda, 1997;
Hoyt, 2013) in showing a self-deflating effect of an elite level of success on goal setting intentions. Furthermore, this study showed that exposure to a role model message that features a citizen environmentalist who successfully reduces their waste can in turn enhance an individual's perceptions of waste reduction attainability, motivation, and intentions. These results are especially useful to strategic communication professionals who may be looking to highlight exemplars in their media strategies.

In regard to COVID-19, we found that an increase in awareness of food waste predicted higher perceptions of waste reduction intentions. Perceptions of food scarcity may inspire others to act more sustainably with food waste as research shows it happens during times of war (Thyberg and Tonjes, 2016). These findings are interesting, yet not surprising. There are several ways that COVID-19 may affect food waste perceptions globally for years to come and the current study supports previous research with these findings (Jribi, Ben Ismail, Doggui, and Debbabi, 2020). Conservationists should consider the COVID-19 pandemic and other newsworthy current events when promoting waste reduction. Times of perceived food scarcity provide an opportunity for environmental agencies and strategic communication professionals to encourage behavior change and share information. The U.S. National Academies of Sciences, Engineering, and Medicine (2020) recommend food waste reduction strategies beyond role model stories, such as school campaigns, discounting suboptimal "ugly" produce, nudging consumers with smaller plates or smaller portions, or removing date labels. Future researchers may consider testing the effectiveness of different strategies for promoting food waste reduction during the pandemic.

There is a critical need for individuals to be aware of their food waste and to be motivated to take steps to decrease their personal waste. The negative effects of food waste on the environment are serious (Kummu et al., 2012), with added unknowns related to COVID-19 and the current trajectory of the pandemic. While half of all food waste happens at the household level in industrialized countries (Parfitt et al., 2010; Stancu et al., 2016), this leaves an equal amount of waste that is generated during processing and distribution. As with all environmental issues, policy and structural changes must be prioritized during the pandemic and beyond.

\section{Study Limitations}

This research is not without limitations. We chose not to include a manipulation check in our main experiment based on research 
from Hauser et al. (2018). There is a possibility that individuals who participated in this research were not paying as close of attention to the stimuli as individuals in the pilot study. However, if individuals did not recognize the message frames in this study, this may also translate to the fact that individuals may not recognize these frames in real life. Individuals have varying levels of interest in food waste reduction, and message exposure effects are circumstantial. The results showed that COVID-19 increased the salience of this issue. Future replications of this research should be considered within different contextual situations. In addition, we did not test information processing outcomes related to our stimuli. Future research may consider cognitive load and attention variables related to role model message reception.

Furthermore, in this study, we analyzed goal setting intentions, and there is a large body of literature that suggests skills and environmental constraints may keep an individual from moving an intention to an action (e.g., Sheeran and Webb, 2016). Future studies may consider attempting to replicate these results using a longitudinal experimental design with a pre and posttest to measure how exposure to various role model messages affects waste reduction behaviors beyond goal setting intentions. Finally, our intention measure did not specifically reference reducing waste or going zero-waste. We made this decision to ensure that all measures featured the same outcome anchors.

\section{CONCLUSION}

Goal setting is an important determinant of achievement and action (Locke and Latham, 1990). Results from the current study showed how exposure to role model stories may be one

\section{REFERENCES}

Abeliotis, K., Lasaridi, K., and Chroni, C. (2014). Attitudes and Behaviour of Greek Households Regarding Food Waste Prevention. Waste Manag. Res. 32 (3), 237-240. doi:10.1177/0734242x14521681

Bandura, A. (1986). The Explanatory and Predictive Scope of Self-Efficacy Theory. J. Soc. Clin. Psychol. 4 (3), 359-373. doi:10.1521/jscp.1986.4.3.359

Bandura, A., and Walters, R. H. (1977). Social Learning Theory, Vol. 1. NJ: Prentice-hall Englewood Cliffs.

Ben Hassen, T., El Bilali, H., and Allahyari, M. S. (2020). Impact of COVID-19 on Food Behavior and Consumption in Qatar. Sustainability. 12 (17), 6973. doi:10. 3390/su12176973

Birmingham, B., and LeQuire, S. L. (2010). "Green Heroes Reexamined: An Evaluation of Environmental Role Models," in Leadership for Environmental Sustainability (Routledge), 121-135.

Boas, T. C., Christenson, D. P., and Glick, D. M. (2020). Recruiting Large Online Samples in the United States and India: Facebook, Mechanical Turk, and Qualtrics. Psrm. 8 (2), 232-250. doi:10.1017/psrm.2018.28

Buzby, J. C., Farah-Wells, H., and Hyman, J. (2014). The Estimated Amount, Value, and Calories of Postharvest Food Losses at the Retail and Consumer Levels in the United States, 121. Washington, DC: USDA-ERS Economic Information Bulletin. Available at: https://www.ers.usda.gov/webdocs/publications/43833/ 43680_eib121.pdf.

Cavallaro, M. C., Boucher, M., and Steelman, T. A. (2017). "Sustainability Champions: Role Models in Sustainability Graduate Education,”. way to communicate the attainability and importance of conservation behaviors. Taken together, the findings from this research confirm that role models that show an achievable level of success can reveal possible routes for reducing food waste, provide behavioral models to facilitate reduction goals, and inspire change. Additionally, considering the relationship between food waste goal setting intentions and COVID-19, there is reason to believe that times of perceived food scarcity may be opportune for promoting food conservation behaviors.

\section{DATA AVAILABILITY STATEMENT}

The raw data supporting the conclusion of this article will be made available by the authors, without undue reservation.

\section{ETHICS STATEMENT}

The studies involving human participants were reviewed and approved by the Virginia Commonwealth University IRB. The patients/participants provided their written informed consent to participate in this study.

\section{AUTHOR CONTRIBUTIONS}

$\mathrm{NHO}, \mathrm{IK}$, and $\mathrm{AH}$ contributed to conception and design of the study. NHO wrote the first draft of the manuscript. NHO and IK informed the statistical analysis. All authors contributed to manuscript revision, read, and approved the submitted version.

Handbook of Theory and Practice of Sustainable Development in Higher Education. Editors W. Leal Filho, M. Mifsud, C. Shiel, and R. Pretorius (Springer International Publishing), Vol. 3, 329-342. doi:10.1007/978-3-31947895-1_20

Chen, C., Chaudhary, A., and Mathys, A. (2020). Nutritional and Environmental Losses Embedded in Global Food Waste. Resour. Conservation Recycling. 160, 104912. doi:10.1016/j.resconrec.2020.104912

Comber, R., and Thieme, A. (2013). Designing beyond Habit: Opening Space for Improved Recycling and Food Waste Behaviors through Processes of Persuasion, Social Influence and Aversive Affect. Pers Ubiquit Comput. 17 (6), 1197-1210. doi:10.1007/s00779-012-0587-1

Doron, N. (2013). Waste Not Want Not: How Fairness Concerns Can Shift Attitudes to Food Waste. London: Fabian Society.

Environmental Protection Agency (2021). Reducing Wasted Food at home. Available at: https://www.epa.gov/recycle/reducing-wasted-food-home (Accessed November 24, 2021).

Graham-Rowe, E., Jessop, D. C., and Sparks, P. (2014). Identifying Motivations and Barriers to Minimising Household Food Waste. Resour. Conservation Recycling. 84, 15-23. doi:10.1016/j.resconrec.2013.12.005

Green-Demers, I., Pelletier, L. G., and Ménard, S. (1997). The Impact of Behavioural Difficulty on the Saliency of the Association between SelfDetermined Motivation and Environmental Behaviours. Can. J. Behav. Sci. /Revue canadienne des Sci. du comportement. 29 (3), 157-166. doi:10.1037/ 0008-400x.29.3.157

Hauser, D. J., Ellsworth, P. C., and Gonzalez, R. (2018). Are Manipulation Checks Necessary? Front. Psychol. 9, 998. doi:10.3389/fpsyg.2018.00998 
Hawken, P. (2017). Drawdown: The Most Comprehensive Plan Ever Proposed to Reverse Global Warming. London, UK: Penguin.

Hayes, A. F. (2019). Introduction to Mediation, Moderation, and Conditional Process Analysis: A Regression-Based Approach. New York, NY: Guilford Publications.

Heen, M. S., Lieberman, J. D., and Miethe, T. D. (2014). A Comparison of Different Online Sampling Approaches for Generating National Samples. Cent. Crime Justice Pol. 1 (9), 1-8. Available at https://www.unlv.edu/sites/default/files/ page_files/27/ComparisonDifferentOnlineSampling.pdf.

Heller, M. (2019). Waste Not, Want Not: Reducing Food Loss and Waste in north America through Life Cycle-Based Approaches. Available at: http://wedocs. unep.org/handle/20.500.11822/27688.

Hoyt, C. L. (2013). Inspirational or Self-Deflating. Soc. Psychol. Personal. Sci. 4 (3), 290-298. doi:10.1177/1948550612455066

Hultman, M. (2013). The Making of an Environmental Hero: A History of Ecomodern Masculinity, Fuel Cells and Arnold Schwarzenegger. Environ. Humanities. 2 (1), 79-99. doi:10.1215/22011919-3610360

Jribi, S., Ben Ismail, H., Doggui, D., and Debbabi, H. (2020). COVID-19 Virus Outbreak Lockdown: What Impacts on Household Food Wastage? Environ. Dev. Sustain. 22, 3939-3955. doi:10.1007/s10668-020-00740-y

Jung, J., Petkanic, P., Nan, D., and Kim, J. H. (2020). When a Girl Awakened the World: A User and Social Message Analysis of Greta Thunberg. Sustainability. 12 (7), 2707. doi:10.3390/su12072707

Kim, J., Rundle-Thiele, S., Knox, K., and Hodgkins, S. (2020). Outcome Evaluation of an Empirical Study: Food Waste Social Marketing Pilot. Soc. Marketing Q. 26 (2), 111-128. doi:10.1177/1524500420918690

Kim, S., Jeong, S.-H., and Hwang, Y. (2013). Predictors of Pro-Environmental Behaviors of American and Korean Students. Sci. Commun. 35 (2), 168-188. doi:10.1177/1075547012441692

Kumar, M., and Dwivedi, S. (2020). Impact of Coronavirus Imposed Lockdown on Indian Population and Their Habits. Int. J. Sci. Healthc. Res. 5 (2), 88-97. Available at https://ijshr.com/IJSHR_Vol.5_Issue.2_April2020/IJSHR_ Abstract.0013.html.

Kummu, M., de Moel, H., Porkka, M., Siebert, S., Varis, O., and Ward, P. J. (2012). Lost Food, Wasted Resources: Global Food Supply Chain Losses and Their Impacts on Freshwater, Cropland, and Fertiliser Use. Sci. Total Environ. 438, 477-489. doi:10.1016/j.scitotenv.2012.08.092

Laato, S., Islam, A. K. M. N., Farooq, A., and Dhir, A. (2020). Unusual Purchasing Behavior during the Early Stages of the COVID-19 Pandemic: The StimulusOrganism-Response Approach. J. Retailing Consumer Serv. 57, 102224. doi:10. 1016/j.jretconser.2020.102224

Leas, E. C., Althouse, B. M., Dredze, M., Obradovich, N., Fowler, J. H., Noar, S. M., et al. (2016). Big Data Sensors of Organic Advocacy: The Case of Leonardo DiCaprio and Climate Change. PLoS One. 11 (8), e0159885. doi:10.1371/ journal.pone. 0159885

Locke, E. A., and Latham, G. P. (1990). A Theory of Goal Setting and Task Performance. Englewood Cliffs, NJ: Prentice-Hall.

Lockwood, P., and Kunda, Z. (1997). Superstars and Me: Predicting the Impact of Role Models on the Self. J. Personal. Soc. Psychol. 73 (Issue 1), 91-103. doi:10. 1037/0022-3514.73.1.91

Luong, K. T., Knobloch-Westerwick, S., and Niewiesk, S. (2020). Superstars within Reach: The Role of Perceived Attainability and Role Congruity in media Role Models on Women's Social Comparisons. Commun. Monogr. 87 (1), 4-24. doi:10.1080/03637751.2019.1622143

MacLeod, A. K., Coates, E., and Hetherton, J. (2008). Increasing Well-Being through Teaching Goal-Setting and Planning Skills: Results of a Brief Intervention. J. Happiness Stud. 9 (2), 185-196. doi:10.1007/s10902-007-9057-2

Martensen, A., Brockenhuus-Schack, S., and Zahid, A. L. (2018). How Citizen Influencers Persuade Their Followers. J. Fashion Marketing Manag. Int. J. 22 (3), 1361-2026. doi:10.1108/jfmm-09-2017-0095

Morgenroth, T., Ryan, M. K., and Peters, K. (2015). The Motivational Theory of Role Modeling: How Role Models Influence Role Aspirants' Goals. Rev. Gen. Psychol. 19 (4), 465-483. doi:10.1037/gpr0000059

Munesue, Y., Masui, T., and Fushima, T. (2015). The Effects of Reducing Food Losses and Food Waste on Global Food Insecurity, Natural Resources, and Greenhouse Gas Emissions. Environ. Econ. Pol. Stud. 17 (1), 43-77. doi:10. 1007/s10018-014-0083-0
Murphy, M. (2019). Zero-waste on Instagram through the Lens of Precautionary Consumption. Gettysburg Soc. Sci. Rev. 3 (1), 3. Available at https://cupola. gettysburg.edu/gssr/vol3/iss1/3.

National Academies of Sciences, Engineering, and Medicine (2020). A National Strategy to Reduce Food Waste at the Consumer Level. Washington, DC: National Academies Press. Available at: https://www.nap.edu/catalog/25876/ a-national-strategy-to-reduce-food-waste-at-the-consumer-level.

Oskamp, S. (1995). Resource Conservation and Recycling: Behavior and Policy. J. Soc. Issues. 51 (4), 157-177. doi:10.1111/j.1540-4560.1995.tb01353.x

Öztürk, D. K. (2016). A Study on Preservice Preschool Teachers' Recycling Intentions in Relation to Parents' Educational Level and Recycling Opportunities. Int. J. Environ. Sci. Education. 11 (5), 949-956. Available at https://eric.ed.gov/?id=EJ1114258.

Parfitt, J., Barthel, M., and Macnaughton, S. (2010). Food Waste within Food Supply Chains: Quantification and Potential for Change to 2050. Phil. Trans. R. Soc. B. 365 (1554), 3065-3081. doi:10.1098/rstb.2010.0126

Plys, E., and Desrichard, O. (2020). Associations between Positive and Negative Affect and the Way People Perceive Their Health Goals. Front. Psychol. 11, 334. doi:10.3389/fpsyg.2020.00334

Principato, L., Secondi, L., Cicatiello, C., and Mattia, G. (2020). Caring More about Food: The Unexpected Positive Effect of the Covid-19 Lockdown on Household Food Management and Waste. Socio-Economic Plann. Sci. 100953, 100953. doi:10.1016/j.seps.2020.100953

Qualtrics (2021). Unlock Breakthrough Insights with Market Research Panels. Seattle, WA.

Quested, T. E., Marsh, E., Stunell, D., and Parry, A. D. (2013). Spaghetti Soup: The Complex World of Food Waste Behaviours. Resour. Conservation Recycling. 79, 43-51. doi:10.1016/j.resconrec.2013.04.011

Quimby, J. L., Seyala, N. D., and Wolfson, J. L. (2007). Social Cognitive Predictors of Interest in Environmental Science: Recommendations for Environmental Educators. J. Environ. Education. 38 (3), 43-52. doi:10.3200/joee.38.3.43-52

Raghunathan, R., and Chandrasekaran, D. (2021). The Association between the Attitude of Food-Waste-Aversion and BMI: An Exploration in India and the United States. J. Consum Psychol. 31, 81-90. doi:10.1002/jcpy.1168

Ramos, I. Q., and Cownie, F. (2020). Female Environmental Influencers on Instagram. Influencer Marketing. London, UK: Routledge, 159-176. doi:10. 4324/9780429322501-12

Richards, T. J., and Rickard, B. (2020). COVID-19 Impact on Fruit and Vegetable Markets. Can. J. Agric. Economics/Revue canadienne d'agroeconomie. 68 (2), 189-194. doi:10.1111/cjag.12231

Rodgers, R. F., Lombardo, C., Cerolini, S., Franko, D. L., Omori, M., Linardon, J., et al. (2021). "Waste Not and Stay at home" Evidence of Decreased Food Waste during the COVID-19 Pandemic from the U.S. And Italy. Appetite. 160, 105110. doi:10.1016/j.appet.2021.105110

Roe, B. E., Bender, K., and Qi, D. (2020). The Impact of COVID-19 on Consumer Food Waste. Appl. Econ. Perspect. Pol. 43, 401-411. doi:10.1002/aepp.13079

Rotter, J. B. (1954). Social Learning and Clinical Psychology. Available at: https:// psycnet.apa.org/psycinfo/2005-06617-000/.

Sheeran, P., and Webb, T. L. (2016). The Intention-Behavior Gap. Social Personal. Psychol. Compass. 10 (9), 503-518. doi:10.1111/spc3.12265

Sivek, D. J., and Hungerford, H. (1990). Predictors of Responsible Behavior in Members of Three wisconsin Conservation Organizations. J. Environ. Education. 21 (2), 35-40. doi:10.1080/00958964.1990.9941929

Stancu, V., Haugaard, P., and Lähteenmäki, L. (2016). Determinants of Consumer Food Waste Behaviour: Two Routes to Food Waste. Appetite. 96, 7-17. doi:10. 1016/j.appet.2015.08.025

Stefanic, N., Iverson, D. C., Caputi, P., and Lane, L. (2017). Examining the Influence of Personal Goal Interference and Attainability on Psychological Distress in Non-metastatic Breast Cancer Patients. Eur. J. Cancer Care. 26 (5), e12494. doi:10.1111/ecc.12494

Stevenson, K. T., Peterson, M. N., Carrier, S. J., Strnad, R. L., Bondell, H. D., KirbyHathaway, T., et al. (2014). Role of Significant Life Experiences in Building Environmental Knowledge and Behavior Among Middle School Students. J. Environ. Education. 45 (3), 163-177. doi:10.1080/00958964.2014.901935

Tenenbaum, G., Spence, R., and Christensen, S. (1999). The Effect of Goal Difficulty and Goal Orientation on Running Performance in Young Female Athletes. Aust. J. Psychol. 51 (1), 6-11. doi:10.1080/00049539908255328 
Thrash, T. M., and Elliot, A. J. (2004). Inspiration: Core Characteristics, Component Processes, Antecedents, and Function. J. Personal. Soc. Psychol. 87 (6), 957-973. doi:10.1037/0022-3514.87.6.957

Thyberg, K. L., and Tonjes, D. J. (2016). Drivers of Food Waste and Their Implications for Sustainable Policy Development. Resour. Conservation Recycling. 106, 110-123. doi:10.1016/j.resconrec.2015.11.016

United States Food and Drug Administration (2021). Food Loss and Waste. Available at: https://www.fda.gov/food/consumers/food-loss-and-waste.

Vroom, V. H. (1994). Work and Motivation. Hoboken, New Jersey: Wiley.

Conflict of Interest: The authors declare that the research was conducted in the absence of any commercial or financial relationships that could be construed as a potential conflict of interest.
Publisher's Note: All claims expressed in this article are solely those of the authors and do not necessarily represent those of their affiliated organizations, or those of the publisher, the editors and the reviewers. Any product that may be evaluated in this article, or claim that may be made by its manufacturer, is not guaranteed or endorsed by the publisher.

Copyright (c) 2022 O'Donnell, Karabas and Hill. This is an open-access article distributed under the terms of the Creative Commons Attribution License (CC BY). The use, distribution or reproduction in other forums is permitted, provided the original author(s) and the copyright owner(s) are credited and that the original publication in this journal is cited, in accordance with accepted academic practice. No use, distribution or reproduction is permitted which does not comply with these terms. 